\title{
Sexual and psychological health of couples with azoospermia in the context of the COVID-19 pandemic
}

\author{
Meng Dong ${ }^{1,2,3}$, Yanqiang Tao ${ }^{4}$, Shanshan $\mathrm{Wu}^{1,2}{ }^{1}$, Zhengtao $\mathbf{L i}^{1}{ }^{1}$, Xiaobin Wang ${ }^{1}$, Jichun Tan ${ }^{\text {Corresp. } 1,2}$ \\ ${ }^{1}$ Center of Reproductive Medicine, Shengjing Hospital of China Medical University, Shengyang, Liaoning, China \\ ${ }^{2}$ Key Laboratory of Reproductive Dysfunction Diseases and Fertility Remodeling of Liaoning Province, Shenyang, China \\ 3 School of Life Sciences, China Medical University, Shenyang, Liaoning, China \\ 4 Faculty of Psychology, Beijing Key Laboratory of Applied Experimental Psychology, Beijing Normal University, Beijing, China \\ Corresponding Author: Jichun Tan \\ Email address: tanjc@sj-hospital.org
}

Background: To date, there have been no reports on the sexual and psychological health of patients with azoospermia during the coronavirus disease 2019 (COVID-19) pandemic. Previous studies on the sexual health of couples with azoospermia are limited and are especially lacking in data on the wives of azoospermic men. Methods: We conducted a case-control cross-sectional study between 1 July 2020 and 20 December 2020. In total, 100 couples with azoospermia comprised the experimental group and 100 couples with normozoospermia comprised the control group. The couples' sexual health was measured using standardised sexual function questionnaires (male: International Index of Erectile Function-15 [IIEF-15] and Premature Ejaculation Diagnostic Tool [PEDT]; female: Female Sexual Function Index [FSFI]) and a self-designed questionnaire to evaluate changes in sexual behaviours (sexual satisfaction, desire, frequency of sexual activity, masturbation, and pornography use) during lockdown. The couples' psychological health was measured using the 7-item Generalized Anxiety Disorder (GAD-7) scale and 9-item Patient Health Questionnaire (PHQ-9). The Actor-Partner Interdependence Model (APIM) was used to analyse the associations between sexual health and psychological health. Results: The IIEF-15 scores ( $53.07 \pm 11.11$ vs. $57.52 \pm 8.57, t=-3.17, p=0.00)$ were lower and the PEDT scores $(6.58 \pm 3.13$ vs. $5.17 \pm 2.22, \mathrm{t}=3.67, p=0.00)$ and incidence of premature ejaculation $\left(\chi^{2}=14.73, p=0.00\right)$ were higher for men with azoospermia than for men with normozoospermia. Compared with those of wives of men with normozoospermia, the total FSFI scores ( $25.12 \pm 5.56$ vs. $26.75 \pm 4.82, t=-2.22, p=0.03$ ) of wives of men with azoospermia were lower. The chi-square test showed that the perceived changes in sexual satisfaction $\left(\chi^{2}=7.22, p=0.03\right)$, frequency of masturbation $\left(\chi^{2}=21.96, p=0.00\right)$, and pornography use $\left(\chi^{2}=10.90, p=0.01\right.$ ) were significantly different between the female 
groups with azoospermia and normozoospermia, but there were no significant changes in sexual behaviour between the male groups. The GAD-7 (men: $7.18 \pm 5.56$ vs. $5.68 \pm 4.58$, $p=0.04$; women: $6.65 \pm 5.09$ vs. $5.10 \pm 3.29, p=0.01$ ) and PHQ-9 scores (men: $10.21 \pm$ 6.37 vs. $7.49 \pm 6.10, p=0.00$; women: $9.07 \pm 6.74$ vs. $7.18 \pm 4.70, p=0.02$ ) were significantly higher for couples with azoospermia than for couples with normozoospermia. The APIM showed that for couples with azoospermia, sexual function negatively correlated with their own anxiety (men: $\beta=-0.22, p=0.00$; women: $\beta=-0.38, p=0.00$ ) and depression symptoms (men: $\beta=-0.21, p=0.00$; women: $\beta=-0.57, p=0.00$ ) but not with their partner's anxiety and depression symptoms $(p>0.05)$. Conclusions: Couples with azoospermia had a lower quality of sexual function with higher levels of psychological distress than couples with normozoospermia. Their sexual health negatively correlated with psychological distress. 


\section{Sexual and psychological health of couples with azoospermia in the context of the COVID-19 pandemic}

3 Running title: Sexual health of azoospermic couples

4 Meng Dong ${ }^{1,2,3}$, Yanqiang Tao ${ }^{4}$, Shanshan $\mathrm{Wu}^{1,2}$, Zhengtao $\mathrm{Li}^{1}$, Xiaobin Wang ${ }^{1}$, Jichun Tan ${ }^{1,2}$ *

$5 \quad{ }^{1}$ Center of Reproductive Medicine, Shengjing Hospital of China Medical University, Shenyang

6 110072, China; Telephone: 86-024-96615-44312

$7 \quad{ }^{2}$ Key Laboratory of Reproductive Dysfunction Diseases and Fertility Remodeling of Liaoning

8 Province, Shenyang 110072, China; Telephone: 86-024-96615-44315

$9{ }^{3}$ School of Life Sciences, China Medical University, Shenyang 110122, China; Telephone: 86024-31939462

${ }^{4}$ Faculty of Psychology, Beijing Key Laboratory of Applied Experimental Psychology, Beijing Normal University, Beijing 10085, China; Telephone: 86-010-58808187 


\section{Abstract}

Background: To date, there have been no reports on the sexual and psychological health of patients with azoospermia during the coronavirus disease 2019 (COVID-19) pandemic. Previous studies on the sexual health of couples with azoospermia are limited and are especially lacking in data on the wives of azoospermic men.

Methods: We conducted a case-control cross-sectional study between 1 July 2020 and 20 December 2020. In total, 100 couples with azoospermia comprised the experimental group and 100 couples with normozoospermia comprised the control group. The couples' sexual health was measured using standardised sexual function questionnaires (male: International Index of Erectile Function-15 [IIEF-15] and Premature Ejaculation Diagnostic Tool [PEDT]; female: Female Sexual Function Index [FSFI]) and a self-designed questionnaire to evaluate changes in sexual behaviours (sexual satisfaction, desire, frequency of sexual activity, masturbation, and pornography use) during lockdown. The couples' psychological health was measured using the 7item Generalized Anxiety Disorder (GAD-7) scale and 9-item Patient Health Questionnaire (PHQ9). The Actor-Partner Interdependence Model (APIM) was used to analyse the associations between sexual health and psychological health.

Results: The IIEF-15 scores $(53.07 \pm 11.11$ vs. $57.52 \pm 8.57, \mathrm{t}=-3.17, p=0.00)$ were lower and the PEDT scores $(6.58 \pm 3.13$ vs. $5.17 \pm 2.22, \mathrm{t}=3.67, p=0.00)$ and incidence of premature 
ejaculation $\left(\chi^{2}=14.73, p=0.00\right)$ were higher for men with azoospermia than for men with normozoospermia. Compared with those of wives of men with normozoospermia, the total FSFI scores $(25.12 \pm 5.56$ vs. $26.75 \pm 4.82, \mathrm{t}=-2.22, p=0.03)$ of wives of men with azoospermia were lower. The chi-square test showed that the perceived changes in sexual satisfaction $\left(\chi^{2}=7.22, p=\right.$ $0.03)$, frequency of masturbation $\left(\chi^{2}=21.96, p=0.00\right)$, and pornography use $\left(\chi^{2}=10.90, p=0.01\right)$ were significantly different between the female groups with azoospermia and normozoospermia, but there were no significant changes in sexual behaviour between the male groups. The GAD-7 (men: $7.18 \pm 5.56$ vs. $5.68 \pm 4.58, p=0.04$; women: $6.65 \pm 5.09$ vs. $5.10 \pm 3.29, p=0.01$ ) and PHQ-9 scores (men: $10.21 \pm 6.37$ vs. $7.49 \pm 6.10, p=0.00$; women: $9.07 \pm 6.74$ vs. $7.18 \pm 4.70, p$ $=0.02$ ) were significantly higher for couples with azoospermia than for couples with normozoospermia. The APIM showed that for couples with azoospermia, sexual function negatively correlated with their own anxiety (men: $\beta=-0.22, p=0.00$; women: $\beta=-0.38, p=$ 0.00 ) and depression symptoms (men: $\beta=-0.21, p=0.00$; women: $\beta=-0.57, p=0.00$ ) but not with their partner's anxiety and depression symptoms $(p>0.05)$.

Conclusions: Couples with azoospermia had a lower quality of sexual function with higher levels of psychological distress than couples with normozoospermia. Their sexual health negatively correlated with psychological distress.

Key words: COVID-19; couples with azoospermia; sexual health; psychological health 


\section{Introduction}

59 The coronavirus disease 2019 (COVID-19) pandemic has brought about challenges to global

60 healthcare and has had a significant effect on individual psychological health and quality of life

61 (Brooks et al., 2020; Huang et al., 2020). The COVID-19 pandemic may have contributed to

62 increased rates of depression, anxiety, and post-traumatic stress disorder in the general population

63 and in COVID-19 survivors (Dutheil et al., 2020; González-Sanguino et al., 2020; Liu et al., 2020;

64 Shuja et al., 2020). Sexual life is an essential part of life (Davison et al., 2009), and sexual health

65 is directly related to mental health and quality of life (World Health Organization [WHO], 2002;

66 World Association for Sexual Health, 2006). Based on the psychological distress caused by this

67 pandemic, it is expected that sexual health would also be affected (Ballester-Arnal et al., 2020).

68 Recent investigations of the effects of the COVID-19 lockdown on sexual health have shown

69 reduced quality of sexual life (Fuchs et al., 2020; Li G et al., 2020; Li W et al., 2020; Yuksel and

70 Ozgor, 2020).

71 Male infertility is a complex multifactorial disease, affecting $7-12 \%$ of men in the general

72 population (Forti et al., 1998; Lotti et al., 2018). Azoospermia is the most serious form of infertility, affecting approximately $1 \%$ of men (Tournaye et al., 2017). Azoospermia is defined as at least two microscopic analyses confirming the absence of spermatozoa after centrifugation of the complete semen sample (American Society for Reproductive Medicine [ASRM], 2018). Being diagnosed with azoospermia can be a devastating experience for infertile couples (Johansson et 
78

79

80

81

82

83

84

85

pregnancy ('firing blanks') may experience both depressive symptoms and somatic anxiety (Lotti et al., 2016). For men with azoospermia, sperm can be obtained only through surgical procedures, such as testicular sperm extraction or epididymal sperm extraction. If the procedure fails, they will not be able to conceive a biological child. Furthermore, the fertilisation and clinical pregnancy rates for couples who attempt to conceive with sperm obtained through a surgical procedure are significantly lower than that for couples with normozoospermia (Vloeberghs et al., 2015). The unfulfilled and strong desire to have children causes significant anxiety among couples with azoospermia, which may have worsened during the COVID-19 pandemic because of the interruption in fertility treatments owing to the lockdown. This interruption in fertility treatments, an uncontrollable and stressful event, has caused increased anxiety and depression in patients with infertility (Ferrero et al., 2020; Boivin et al., 2020; Ben-Kimhy et al., 2020; Turocy et al., 2020). Stress related to the lockdown, postponed fertility care, and uncertainty can affect mental wellbeing, especially in men with azoospermia, whose pre-pandemic levels of distress and functional impairment are typically higher than those of patients with other types of infertility.

There are few studies focusing on the sexual health of couples with azoospermia, but they lack data on the wives of men with azoospermia (Kızlay et al., 2018; Lotti et al., 2016). Therefore, an investigation of the sexual health of couples with azoospermia is warranted. This study primarily aimed to investigate the sexual health (including sexual function and perceived changes in sexual behaviours during lockdown) and psychological health (including anxiety and depression status) of couples with azoospermia compared with those of couples with normozoospermia. Moreover, 
we aimed to explore the association between sexual health and psychological health in couples with azoospermia using the Actor-Partner Interdependence Model (APIM).

\section{Materials and methods}

\section{Participant selection}

A case-control cross-sectional questionnaire survey was administered at the Center of Reproductive Medicine of Shengjing Hospital of China Medical University between 1 July 2020 and 20 December 2020. The experimental group consisted of men with azoospermia and their wives, whereas the control group consisted of men with normozoospermia (according to WHO semen examination standards, 2010) and their wives. All participants were recruited from our Reproductive Medicine Center. The semen test result of the men in the control group was normal (men with normozoospermia), and no spouse was diagnosed with infertility. Men taking drugs (e.g. selective serotonin reuptake inhibitors, tricycle antidepressants, and phosphodiesterase type 5 inhibitors) that may affect their ejaculatory and erectile function and/or mental state were excluded (Gao et al., 2013). All participants were aware of their fertility status (including semen status) before completing the questionnaire. Before enrolment in the study, all participants were informed of the voluntary and anonymous nature of the study design and that their privacy would be protected. None of the participants had any biological children.

The questionnaires were completed in a private room at the Center of Reproductive Medicine of Shengjing Hospital of China Medical University to fully ensure participants' privacy, and no 
118

119

120

121

122

123

124

125

126

127

128

129

130

131

132

133

134

135

136

137

spouses were present. Participants were not compensated in any form. Participants who provided inconsistent answers were excluded (e.g. in the questionnaire focused on sexual function, 'did not attempt intercourse' was selected in one question but not others).

\section{Measures}

We used a self-designed questionnaire and five standardised questionnaires. All used questionnaires are validated in Chinese language.

\section{Demographic variables}

Data on patients' baseline information, including age, height, weight, occupation, educational level, work or life stress level, and lifestyle habits (such as frequency of physical exercise, smoking status, and drinking status), were collected.

\section{Men's sexual function}

Men's sexual function was assessed using the International Index of Erectile Function-15 (IIEF15) and Premature Ejaculation Diagnostic Tool (PEDT) and was based on their sexual status in the preceding 4 weeks. The IIEF-15 includes 15 items covering 5 domains of male sexual function (erectile function, orgasmic function, sexual desire, intercourse satisfaction, and overall satisfaction). The total score ranges from 6 to 45 , with Cronbach's alpha values $\geq 0.91$ (Rosen et al., 1997; Corona et al., 2006). The presence and severity of ED were based on the IIEF-15 score, with the severity of ED represented as follows: $26-30$, none; $22-25$, mild; $17-21$, mild to moderate; 11-16, moderate; and < 11, severe (Cappelleri et al., 1999).

The PEDT includes 5 items, which are scored on a 5-point scale from 0 to 4 , with a total severity 
138 score ranging from 0 to 20 . A PEDT score $\leq 8$ indicated no premature ejaculation (PE), 9-10

139 indicated probable PE, and $\geq 11$ indicated implied PE. Cronbach's alpha value was 0.78 (Symonds

140 et al., 2007).

141 Women's sexual function

142 Female sexual function was assessed using the Female Sexual Function Index (FSFI), which

143 includes 19 items and 6 domains of sexual function (desire, arousal, lubrication, orgasm,

144 satisfaction, and coital pain) based on the sexual status in the preceding 4 weeks. The scores for

145 each domain range from 1.2 to 6 or from 0 to 6 , and the total score ranges from 2 to 36 , with

146 Cronbach's alpha value $\geq 0.82$ (Rosen et al., 2000). An FSFI total score $\leq 23.45$ (Chinese cut-off)

147 indicated that the woman might have sexual dysfunction (Ma et al., 2014; Lo et al., 2018).

\section{Sexual behaviours during lockdown}

149 We measured five aspects of self-reported changes in sexual behaviours during the lockdown using

150 five questions, which were adopted from previous studies' questionnaires (Li G et al., 2020; Li W

151 et al., 2020). Change in sexual desire was assessed by asking the following question: 'Compared

152 with that before the COVID-19 pandemic, how has your sexual desire changed'? Change in sexual

153 frequency was assessed by asking the following question: 'Compared with that before the COVID-

15419 pandemic, how has your sexual frequency changed'? Change in sexual satisfaction was

155 evaluated by asking the following question: 'Compared with that before the COVID-19 pandemic,

156 how has your sexual satisfaction changed'? The answers to the above three questions were set as

157 follows: increased, unchanged, and decreased. Change in frequency of masturbation was assessed 
158

159

160

161

162

163

164

165

166

167

168

169

170

171

172

173

174

175

176

177

by asking the following question: 'How has your frequency of masturbation changed compared with that before the COVID-19 pandemic'? Change in frequency of pornography use was evaluated by asking the following question: 'How has your frequency of pornography use changed compared with that before the COVID-19 pandemic'? The answers to the above two questions were set as follows: none, increased, unchanged, and decreased.

\section{Psychological health}

Anxiety symptoms were evaluated using the 7-item Generalized Anxiety Disorder scale (GAD-7). The items are scored on a 4-point scale, from 0 to 3 , and the total score ranges from 0 to 21 . The cut-off score of $\geq 10$ was used to assess the presence of anxiety (Lowe et al., 2008).

Depression symptoms were evaluated using the 9-item Patient Health Questionnaire (PHQ-9), with Cronbach's $\alpha$ value ranging from 0.73 to 0.95 . The items are scored on a 4-point scale from 0 to 3 , with a total severity score ranging from 0 to 27 . The cut-off score of $\geq 10$ was used to assess the presence of depression (Kroenke et al., 2001).

In this study, a question on COVID-19-related anxiety ('Does the novel coronavirus pneumonia pandemic make you anxious') was also asked, in which respondents rated their anxiety as severe, slight, or none.

\section{Statistical analyses}

Data analyses were performed using the statistical software Statistical Package for the Social Sciences (version 22.0; International Business Machines Corp., Armonk, NY, USA). Results are presented in a tabular format. Categorical variables are summarised as counts and percentages, in 
178

179

180

181

182

184

addition to continuous measures with counts, means, and standard deviations (SDs). The chisquare test was used to compare categorical data, and the independent t-test and one-way analysis of variance (ANOVA) were used to compare numerical data. Effect sizes were used to evaluate the strength of each statistical analysis and were measured with Cohen's d for independent t-tests, Cramer's V for chi-square $\left(\chi^{2}\right)$ tests, and $\eta^{2}$ for ANOVA tests.

We used the APIM (Cook and Snyder, 2005) to assess the association between sexual function and psychological health for both sexes. We used the R package 'lavaan' for calculating the mediation effects. The actor effect was defined as the effect of an individual's sexual function on his/her own depression and anxiety symptoms, and the partner effect was defined as the effect of an individual's sexual function on his/her partner's depression and anxiety symptoms (Fernandes et al., 2021). The overall fitting model and goodness-of-fit were evaluated with the following indices: degrees of freedom values $\left(\chi^{2} / d f\right)<3$, root mean square error of approximation (RMSEA) $<0.10$, standardised root mean square residual $(S R M R)<0.10$, normed fit index $(N F I)>0.90$, and comparative fit index $(C F I)>0.90(\mathrm{Ryu}, 2014)$.

A two-tailed $p$ value $<0.05$ indicated statistical significance for all tests.

\section{Ethical approval}

The study protocol was approved by the Institutional Review Board for Research on Human Subjects at the Center of Reproductive Medicine (approval number 2020PS009F). 
198

199

200

201

202

203

204

205

206

207

208

209

210

211

212

213

214

215

216

217

\section{Participant response and demographic characteristics}

A total of 128 couples (men diagnosed with azoospermia and their wives) belonging to the experimental group participated in the study; 28 couples were excluded because they provided inconsistent answers and/or failed to answer all questions (18 failed to answer all questions and 10 provided inconsistent answers). A total of 135 couples (men diagnosed with normozoospermia and their wives) belonging to the control group participated in the study; 35 couples were excluded (23 failed to answer all questions and 12 provided inconsistent answers). Ultimately, the responses of 200 couples (100 couples with azoospermia, 100 couples with normozoospermia) were included in the analysis (response rate, $76 \%$ ).

Table 1 shows participants' demographic characteristics. The average ages were 34.52 (SD 4.71) years for patients with azoospermia and 34.95 (SD 4.00) years for patients with normozoospermia $(\mathrm{t}=-0.70, p=0.49)$. The average ages of wives in the corresponding groups were $32.76(\mathrm{SD} 4.32)$ and $33.51(\mathrm{SD} 4.42)$ years, respectively $(\mathrm{t}=-1.21, p=0.23)$. There were no significant differences in body mass index, income, educational levels, lifestyle factors (smoking status, drinking status, frequency of physical exercise), and stress levels between the two male groups $(p>0.05)$. Educational levels $\left(\chi^{2}=15.78, p=0.00\right)$ and drinking status $\left(\chi^{2}=8.11, p=\right.$ 0.03) were significantly different between the two female groups (Table 1).

Comparison of sexual function and behaviours between couples with azoospermia and normozoospermia

The results of the independent t-test showed that the total IIEF-15 score (53.07 \pm 11.11 vs. 57.52 
$218 \pm 8.57, \mathrm{t}=-3.17, p=0.00$ ) and ratings from four domains of male sexual function (erectile function $219[23.25 \pm 5.13$ vs. $24.82 \pm 4.18, \mathrm{t}=-2.37, p=0.02]$, orgasmic function $[7.34 \pm 1.82$ vs. $8.04 \pm 1.48$, $220 \mathrm{t}=-2.98, p=0.00]$, intercourse satisfaction $[9.45 \pm 2.71$ vs. $10.55 \pm 2.18, \mathrm{t}=-3.16, p=0.00]$, 221 and overall satisfaction $[6.96 \pm 2.24$ vs. $7.67 \pm 1.86, \mathrm{t}=-2.44, p=0.02]$ ) were lower for men with 222 azoospermia than for men with normozoospermia. In contrast, the PEDT scores $(6.58 \pm 3.13$ vs. $2235.17 \pm 2.22, \mathrm{t}=3.67, p=0.00)$ and PE incidence $\left(\chi^{2}=14.73, p=0.00\right)$ were higher for men with 224 azoospermia than for men with normozoospermia. The chi-square test showed that sexual 225 satisfaction $\left(\chi^{2}=7.32, p=0.02\right)$ was lower in men with azoospermia than in men with normozoospermia. Results of the independent t-test showed that the frequency of sexual activity was lower in men with azoospermia than in men with normozoospermia (4.14 \pm 2.72 vs. $5.04 \pm$ $2.25, \mathrm{t}=-2.55, p=0.01)$. Sexual desire scores $(6.07 \pm 1.37$ vs. $6.24 \pm 1.29, \mathrm{t}=-0.90, p=0.37)$ and incidence of $\operatorname{ED}\left(\chi^{2}=6.40, p=0.09\right)$ were not significantly different between the two groups (Table 2).

For the wives, the results of the independent t-test showed that the total FSFI scores $(25.12 \pm$ 5.56 vs. $26.75 \pm 4.82, \mathrm{t}=-2.22, p=0.00)$ and ratings from three of the six domains of female sexual function (orgasm $[4.22 \pm 1.26$ vs. $4.60 \pm 1.03, \mathrm{t}=-2.33, p=0.02]$, satisfaction $[4.10 \pm 1.39$ vs. $4.72 \pm 1.09, \mathrm{t}=-3.51, p=0.00]$, and coital pain $[4.72 \pm 1.06$ vs. $6.04 \pm 0.92, \mathrm{t}=-9.40, p=$ 0.02]) were lower in the group with azoospermia than in the group with normozoospermia. The chi-square test revealed that sexual satisfaction was lower in the group with azoospermia than in

237 the group with normozoospermia $\left(\chi^{2}=14.18, p=0.00\right)$. The results of the independent t-test 
238 indicated that the scores for sexual desire, sexual arousal ability, and vaginal lubricity were not

239 significantly different between the two groups $(p>0.05)$ (Table 3$)$.

240 Changes in sexual behaviours of couples with azoospermia and

241

242

243

244

24

246

247

248

249

250

251

252

253

254

255

256

257

\section{normozoospermia during the lockdown}

Regarding changes in sexual behaviours among men, the chi-square test revealed no significant differences in the perceived changes in sexual satisfaction $\left(\chi^{2}=0.71, p=0.06\right)$, sexual desire $\left(\chi^{2}\right.$ $=0.00, p=1.00)$, frequency of sexual activity $\left(\chi^{2}=0.23, p=0.89\right)$, frequency of masturbation $\left(\chi^{2}\right.$ $=4.62, p=0.20)$, or pornography use $\left(\chi^{2}=2.71, p=0.44\right)$ between the two groups (Table 4).

Among women, the chi-square test showed that the perceived changes in sexual satisfaction $\left(\chi^{2}=7.22, p=0.03\right)$, frequency of masturbation $\left(\chi^{2}=21.96, p=0.00\right)$, and pornography use $\left(\chi^{2}=\right.$ 10.90, $p=0.01$ ) were significantly different between the group with azoospermia and normozoospermia. However, there were no significant differences in the perceived changes in sexual desire $\left(\chi^{2}=2.79, p=0.25\right)$ or frequency of sexual activity $\left(\chi^{2}=1.73, p=0.42\right)$ (Table 4$)$.

\section{Psychological health of couples with azoospermia and normozoospermia in}

\section{the context of the COVID-19 pandemic}

The GAD-7 scores (men: $7.18 \pm 5.56$ vs. $5.68 \pm 4.58, \mathrm{t}=-2.08, p=0.04$; women: $6.65 \pm 5.09$ vs.

$5.10 \pm 3.29, \mathrm{t}=2.56, p=0.01)$ and PHQ-9 scores (men: $10.21 \pm 6.37$ vs. $7.49 \pm 6.10, \mathrm{t}=3.08, p$ $=0.00$; women: $9.07 \pm 6.74$ vs. $7.18 \pm 4.70, \mathrm{t}=2.30, p=0.02$ ) were significantly higher for couples with azoospermia than for couples with normozoospermia. The incidence rates of anxiety, depression, and COVID-19-related anxiety were higher among couples with azoospermia than 
258 among couples with normozoospermia $(p<0.05)$ (Table 5).

259

260

261

262

263

264

265

266

267

268

269

270

271

272

273

274

275

276

277

0

\section{Association between sexual function and psychological health in couples with}

\section{azoospermia}

Results of the APIM showed that for couples with azoospermia, sexual function negatively correlated with their own anxiety (men: $\beta=-0.22$, standard error $(S E)=0.04, Z=-5.08, p=0.00$; women: $\beta=-0.38, S E=0.09, Z=-4.46, p=0.00)$ and depression symptoms (men: $\beta=-0.21, S E$ $=0.05, Z=-4.46, p=0.00$; women: $\beta=-0.57, \mathrm{SE}=0.12, \mathrm{Z}=-4.89, p=0.00)$ but not with their partner's anxiety (men: $\beta=-0.00, \mathrm{SE}=0.04, \mathrm{Z}=-0.07, p=0.94$; women: $\beta=-0.07, \mathrm{SE}=0.09$, $\mathrm{Z}=-0.77, p=0.44$ ) and depression symptoms (men: $\beta=0.01, \mathrm{SE}=0.05, \mathrm{Z}=0.25, p=0.80$; women: $\beta=-0.12, \mathrm{SE}=0.11, \mathrm{Z}=-1.08, p=0.28)$. The model revealed a good overall fit $(\chi 2 / d f$ $=0.00, C F I=1.00, R M S E A=0.00, S R M R=0.00, N F I=1.00)$. None of the studied partner effects were significant, but the actor effects were significant (Fig 1).

\section{Discussion}

This is the first study to evaluate the sexual health and psychological health of couples with azoospermia in the context of COVID-19 pandemic. Given the rarity of the diagnosis and the delicate nature of the study, our sample of couples with azoospermia is relatively impressive. Our study found that the incidence of sexual dysfunction in couples with azoospermia was significantly higher than that in couples with normozoospermia. Couples with azoospermia experienced higher rates of anxiety and depression than couples with normozoospermia. The APIM showed that 
278

279

280

281

282

283

284

285

286

287

288

289

290

291

292

293

294

295

296

297

sexual function negatively correlated with the couples' own anxiety and depression symptoms but not with their partner's anxiety and depression symptoms.

Our study systematically compared the sexual health of couples with azoospermia as studies focusing on the sexual health of couples with azoospermia are limited (Kızılay et al., 2018) and are especially lacking in data on the wives of men with azoospermia. In couples with azoospermia, the incidence of sexual dysfunction was significantly higher than that in the control group. The scores for ED, orgasmic function, intercourse satisfaction, and overall satisfaction were significantly lower for men with azoospermia than for men with normozoospermia. This is consistent with the result of a previous study, which found an association between the severity of semen quality impairment and sexual dysfunction (Lotti et al., 2016). Lotti et al'.s study (2016) found that infertile men showed more ejaculatory latency and reduced sexual health, sexual desire, and orgasmic function than fertile men. In our study, the incidence of PE in men with azoospermia was higher than that in men with normozoospermia, which is consistent with the findings of previous studies (Lotti et al. 2016; Gao et al., 2014).

Notably, there are significantly few studies on the sexual health of wives of the men with azoospermia. Our study found that the FSFI scores (orgasm, sexual satisfaction, coital pain) of the wives of men with azoospermia were significantly lower than those of the wives of men with normozoospermia. The incidence of sexual dysfunction was insignificantly higher in the wives of men with azoospermia than in the wives of men with normozoospermia $(p=0.05)$, which may be owing to the cut-off value (Wiegel et al., 2005) and relatively small sample size. Despite this, we 
298

299

300

301

302

303

304

305

306

307

308

309

310

311

312

313

314

315

316

317

believe that the wives of the men with azoospermia have a lower quality of sexual function than

those of men with normozoospermia, as evidenced by the FSFI scores for orgasm function and intercourse pain $(p<0.05)$ and a $p$ value of 0.05 for the incidence of sexual dysfunction. Our results are consistent with those from the study by Kiz1lay et al. (2018), in which the FSFI scores of the wives of men with azoospermia were significantly lower than those of the wives of men with oligospermia or normozoospermia. Previous studies have also reported that female sexual function is significantly related to male sexual function in the general population (Jiann et al., 2013). In our study, the sexual function of couples with azoospermia was significantly lower than that of the control group, though the wives of men with azoospermia did not have organic diseases that affect sexual function. Female sexual function can be influenced by various factors, such as biological (hormonal and pelvic floor disorders), psychosexual (emotional and affective), and contextual (relationship discord, partner's health problems, and sexual dysfunction) factors (Graziottin et al., 2006). Therefore, the diagnosis of azoospermia with perceived loss of masculinity and virility (Reder et al., 2009), as well as the unfulfilled desire to conceive and psychological distress, may negatively affect women's sexual function. azoospermia during the lockdown. Our study found that there were no significant perceived changes in sexual behaviours in men with azoospermia compared with that in men with normozoospermia. However, perceived changes in sexual satisfaction, frequency of masturbation, and pornography use were more frequent among the wives of men with azoospermia than among 
318 the wives of men with normozoospermia. We observed that the rate of increased frequency of

319 pornography use and masturbation in wives of men with azoospermia was significantly higher than

320 that of the control group. An online survey conducted in England and Spain reported that $10 \%$ of

321 the participants masturbated more than usual during the lockdown (Ibarra et al., 2020). Increased

322 masturbation frequency and frequent pornography use are related to a decline in the quality of

323 sexual life and sexual satisfaction (Brody and Costa, 2009; Böthe et al., 2020), which is consisted

324 with our study that the rate of decreased sexual satisfaction in the group with azoospermia was

325 significantly higher than that of the control group. Pornography use plays a role in coping with

326 negative moods, stress, and anxiety (Wordecha et al., 2018). Increased use of pornography is

327 related to the need for distraction from loneliness, distress, boredom, or pandemic-related emotions

328 (Grubbs, 2020). Therefore, the perceived changes in sexual behaviours we have observed may be

329 related to the high incidence rate of depression and anxiety symptoms in patients with

330 azoospermia.

331 A recently conducted study reported that changes in sexual behaviours are closely related to

332 psychological emotions (Carvalho et al., 2021). A previous study also evaluated the moderating

333 effects of sexual activity on mental health and sexual health during the COVID-19 pandemic

334 (Mollaioli et al., 2021). Because our study does not utilise a pre-post repeated measures design,

335 we do not know the mental health scores of couples with azoospermia before the COVID-19

336 pandemic. Large further longitudinal multicentre clinical trials should be conducted to further

337 confirm the association between changes in sexual behaviours and mental health. 

allows the analysis of dyads in one model (Fernandes et al., 2021), which can determine whether the sexual function of patients with azoospermia is related not only to one's own psychological status but also to the psychological health of their partner. Our model showed that sexual function negatively correlated with patient's own anxiety and depression symptoms but not with their partner's anxiety and depression symptoms in couples with azoospermia. This is the first time that the APIM has been used to investigate the association between sexual function and psychological health in patients with azoospermia.

During the treatment of infertility, it is significantly important to consider not only the couple's reproductive health but also their sexual and psychological health. It is vital to detect these issues early and treat them appropriately with sexological and psychological therapy, especially during the pandemic. time point during the lockdown and therefore cannot assess changes accurately. Second, because 357 the questionnaire was anonymous, we could not obtain patient clinical data, such as information 
358 regarding azoospermia classification or serum hormone levels, which are indicators that can affect

359 the sexual health of patients with azoospermia. However, if the questionnaires had been

360 identifiable by name, the patients with azoospermia might have been reluctant to participate in this

361 study or unwilling to answer truthfully. Finally, the current study included the use of self-designed

362 questions (in reference to other studies on changes in sexual behaviours during the pandemic [Li

363 G et al., 2020; Li W et al., 2020]) and relied on self-reported cross-sectional data from local

364 convenient samples. Thus, our findings need to be confirmed through further longitudinal

365 multicentre clinical trials.

366

367 Conclusions

368 Couples with azoospermia had a lower quality of sexual function with higher levels of 369 psychological distress than couples with normozoospermia. In couples with azoospermia, the sexual function negatively correlated with their own and depression symptoms but not with their partner's anxiety and depression symptoms. The effects observed in the wives in the APIM are important to investigating effects on both members of the couple and not just the afflicted one. provide sexual and psychological health counselling to patients with infertility, especially during the pandemic. 


\section{References}

377 Ballester-Arnal Rafael., Nebot-Garcia Juan E., Ruiz-Palomino Estefanía., Giménez-García

378 Cristina., Gil-Llario María Dolores. "INSIDE" Project on Sexual Health in Spain: Sexual Life

379 During the Lockdown Caused by COVID-19. Sex Res Social Policy 2020; undefined: 1-19.

380

381

382

383

384

385

386

387

388

389

390

391

392

393

394

395
Ben-Kimhy Reut., Youngster Michal., Medina-Artom Tamar R., Avraham Sarit., Gat Itai., Marom

Haham Lilach., Hourvitz Ariel., Kedem Alon. Fertility patients under COVID-19: attitudes, perceptions and psychological reactions. Hum Reprod 2020;35: 2774-2783.

Boivin J, Harrison C, Mathur R, Burns G, Pericleous-Smith A, Gameiro S. Patient experiences of fertility clinic closure during the COVID-19 pandemic: appraisals, coping and emotions. Hum Reprod 2020; 35(11): 2556-2566.

Bőthe B, Tóth-Király I, Potenza MN, Orosz G, Demetrovics Z. High-Frequency Pornography Use May Not Always Be Problematic. J Sex Med 2020; 17(4):793-811.

Brody S, Costa RM. Satisfaction (sexual, life, relationship, and mental health) is associated directly with penile-vaginal intercourse, but inversely with other sexual behavior frequencies. J Sex Med 2009; 6(7):1947-1954.

Brooks Samantha K., Webster Rebecca K., Smith Louise E., Woodland Lisa., Wessely Simon., Greenberg Neil., Rubin Gideon James. The psychological impact of quarantine and how to reduce it: rapid review of the evidence. Lancet 2020; 395:912-920.

Cappelleri JC, Rosen RC, Smith MD, Mishra A, Osterloh IH. Diagnostic evaluation of the erectile function domain of the International Index of Erectile Function. Urology 1999; 54:346-51.

Peer] reviewing PDF | (2021:04:60583:3:0:NEW 15 Aug 2021) 
396 Carvalho Joana., Campos Priscila., Carrito Mariana., Moura Catarina., Quinta-Gomes Ana.,

397 Tavares Inês., Nobre Pedro. The Relationship Between COVID-19 Confinement, Psychological

398 Adjustment, and Sexual Functioning, in a Sample of Portuguese Men and Women. J Sex Med

399 2021; undefined: undefined.

400 Cook William L,Snyder Douglas K, Analyzing nonindependent outcomes in couple therapy using

401 the actor-partner interdependence model. .J Fam Psychol 2005; 19: 133-41.

402 Corona G, Jannini EA, Maggi M. Inventories for male and female sexual dysfunctions. Int J Impot

403 Res 2006; 18:236-250.

404 Davison SL, Bell RJ, La CM, Holden SL., Davis SR. The relationship between self-reported sexual

405 satisfaction and general well-being in women. J Sex Med 2009; 6:2690-2697.

406 Dutheil Frédéric,Mondillon Laurie,Navel Valentin. PTSD as the second tsunami of the SARS-

407 Cov-2 pandemic. Psychol Med 2020, undefined: 1-2.

408 Eugster A,Vingerhoets A J. Psychological aspects of in vitro fertilization: a review. Soc Sci Med

409 1999; 48: 575-89.

410 Fernandes J, Pedro J, Costa M E, Martins M V. Effect of depression and anxiety on sexual

411 functioning in couples trying to conceive with and without an infertility diagnosis. Psychol Health

412 2021, undefined: 1-18.

413 Ferrero S, Scala C, Altieri M, Barra F. Impact of COVID-19 pandemic on the psychological status

414 of infertile patients who had in vitro fertilization treatment interrupted or postponed. Oral

415 presented at: 36th Annual meeting of the ESHRE; July 8 2020; Volume 35, supp 1, i125 
416 Fuchs A, Matonóg A, Pilarska J ,Sieradzka P, Szul M, Czuba B, Drosdzol CA. The Impact of

417 COVID-19 on Female Sexual Health .Int J Environ Res Public Health 2020;17: undefined.

418 Gao J, Zhang X, Su P, Liu J, Shi K, Hao Z, Zhou J, Liang C. Relationship between sexual 419 dysfunction and psychological burden in men with infertility: a large observational study in China.

420 J Sex Med 2013; 10:1935-1942.

421 Gao Jingjing., Zhang Xiansheng., Su Puyu., Peng Zhen., Liu Jishuang., Xia Lei., Lu Zhaoxiang.,

422 Yang Jiajia., Tang Dongdong., Gao Pan., Zhou Jun., Hao Zongyao., Liang Chaozhao. The impact

423 of intravaginal ejaculatory latency time and erectile function on anxiety and depression in the four

424 types of premature ejaculation: a large cross-sectional study in a Chinese population. J Sex Med $425 \quad 2014 ; 11: 521-528$.

426 González-Sanguino Clara., Ausín Berta., Castellanos Miguel Ángel., Saiz Jesús., López-Gómez 427 Aída., Ugidos Carolina., Muñoz Manuel. Mental health consequences during the initial stage of 428 the 2020 coronavirus pandemic (COVID-19) in Spain. Brain Behav Immun 2020; 87: 172-76.

429 Graziottin A, Dennerstein L, Alexander JL, Giraldi A, Whipple B. Classification, etiology, and key 430 issues in female sexual disorders. In: Porst H, Buvat J; The Standards Committee of the 431 International Society for Sexual Medicine, eds.Standard practice in sexual medicine. 432 Massachusetts, MA: Blackwell Publishing; 2006:305-14.

433 Grubbs J. B. Porn use is up, thanks to the pandemic. The Conversation. April 8, 2020. $434 \mathrm{https}$ //theconversation.com/porn-use-is-up-thanks-to-the-pandemic-134972.

435 Huang Xiaoyi., Wei Fengxiang., Hu Liang., Wen Lijuan., Chen Ken. Epidemiology and Clinical 
436 Characteristics of COVID-19. Arch Iran Med 2020; 23:268-271.

437 Ibarra François Peinado., Mehrad Mehri., Di Mauro Marina., Godoy María Fernanda Peraza., Cruz

438 Eduard García., Nilforoushzadeh Mohammad Ali., Russo Giorgio Ivan. Impact of the COVID-19

439 pandemic on the sexual behavior of the population. The vision of the east and the west. Int.Braz.

440 J. Urol 2020; 46: 104-112.

441 Jiann Bang-Ping., Su Cheng-Chen., Tsai Jeng-Yu. Is female sexual function related to the male

442 partners' erectile function? J Sex Med 2013;10: 420-9.

443 Johansson Marianne, Hellström Anna-Lena, Berg Marie. Severe male infertility after failed ICSI

444 treatment--a phenomenological study of men's experiences. Reprod Health 2011;8: 4.

445 Kızılay Fuat,Şahin Mehmet,Altay Barış. Do sperm parameters and infertility affect sexuality of 446 couples? Andrologia 2018;50: undefined.

447 Kroenke K, Spitzer RL, Williams JB. The PHQ-9: validity of a brief depression severity measure.

$448 \quad$ J Gen Intern Med 2001; 16:606-613.

449 Liu X, Luo WT, Li Y, Li CN, Hong ZS, Chen HL, Xiao F, Xia JY. Psychological status and 450 behavior changes of the public during the COVID-19 epidemic in China. Infect Dis Poverty 2020; $4519: 58$.

452 Li G, Tang D, Song B Wang C, Qunshan S, Xu C., Geng H, Wu H, He X, Cao Y. Impact of the 453 COVID-19 Pandemic on Partner Relationships and Sexual and Reproductive Health: Cross454 Sectional, Online Survey Study. J Med Internet Res 2020; 22: e20961.

455 Li W, Li G, Xin C, Wang Y, Yang S. Changes in sexual behaviors of young women and men 
456 during the coronavirus disease 2019 outbreak: a convenience sample from the epidemic area. J

457 Sex Med 2020; 17: 1225-1228.

458 Lo Sue Seen-Tsing,Kok Wai-Ming. Prevalence and Risk Factors for Sexual Problems and Distress

459 in Chinese Unmarried Young Women: An Observational Study. J Sex Med 2018; 15: 1620-1628.

460 Lotti F., Corona G., Castellini G., Maseroli E., Fino M G., Cozzolino M., Maggi M. Semen quality

461 impairment is associated with sexual dysfunction according to its severity. Hum Reprod 2016; 31:

$462 \quad 2668-2680$.

463 Lotti F, Corona G, Rastrelli G, Forti G, Jannini EA, Maggi M. Clinical correlates of erectile

464 dysfunction and premature ejaculation in men with couple infertility. J Sex Med 2012; 9:2698-

4652707.

466 Löwe Bernd., Decker Oliver., Müller Stefanie., Brähler Elmar., Schellberg Dieter., Herzog

467 Wolfgang., Herzberg Philipp Yorck. Validation and standardization of the Generalized Anxiety

468 Disorder Screener (GAD-7) in the general population. Med Care 2008; 46:266-274.

469 Ma Jiehua., Pan Lianjun., Lei Yu., Zhang Aixia., Kan Yanjing. Prevalence of female sexual

470 dysfunction in urban Chinese women based on cutoff scores of the Chinese version of the Female

471 Sexual Function Index: a preliminary study. J Sex Med 2014;11:909-919.

472 Mollaioli Daniele., Sansone Andrea., Ciocca Giacomo., Limoncin Erika., Colonnello Elena., Di

473 Lorenzo Giorgio., Jannini Emmanuele A. Benefits of Sexual Activity

474 on Psychological, Relational, and Sexual Health During the COVID-19 Breakout. J Sex

475 Med 2021, 18: 35-49. 
476 Practice Committee of the American Society for Reproductive Medicine in collaboration with the

477 Society for Male Reproduction and Urology. Evaluation of the azoospermic male: a committee 478 opinion. Fertil Steril 2018, 109: 777-782.

479 Qiu J, Shen B, Zhao M, Wang Z, Xie B, Xu Y. A nationwide survey of psychological distress 480 among Chinese people in the COVID-19 epidemic: implications and policy recommendations.

481 Gen Psychiatr 2020; 33: e100213.

482 Reder F, Fernandez A, Ohl J. Does sexuality still have a place for couples treated with assisted 483 reproductive techniques? J Gynecol Obstet Biol Reprod 2009;38, 377-388.

484 Rosen R., Brown C., Heiman J., Leiblum S., Meston C., Shabsigh R., Ferguson D., D'Agostino R. 485 The Female Sexual Function Index (FSFI): a multidimensional self-report instrument for the 486 assessment of female sexual dysfunction. J Sex Marital Ther 2000; 26:191-208.

487 Rosen R C., Riley A., Wagner G., Osterloh I H., Kirkpatrick J., Mishra A. The international index 488 of erectile function (IIEF): a multidimensional scale for assessment of erectile dysfunction. 489 Urology 1997; 49:822-830.

490 Ryu Ehri. Model fit evaluation in multilevel structural equation models.Front Psychol 2014; 5: 81.

491 Shuja KH, Aqeel M, Jaffar A, Ahmed A. COVID-19 pandemic and impending global mental 492 health implications. Psychiatr Danub 2020; 32(1):32-35.

493 Song Jingyu., Gu Longjie., Ren Xinling., Liu Yang., Qian Kun., Lan Ruzhu., Wang Tao., Jin Lei., 494 Yang Jun., Liu Jihong. Prediction model for clinical pregnancy for ICSI after surgical sperm 495 retrieval in different types of azoospermia. Hum Reprod 2020; 35: 1972-1982. 
496 Symonds T, Perelman MA, Althof S, Giuliano F, May K,Abraham L, Crossland A, Morris M.

497 Development and validation of a premature ejaculation diagnostic tool. Eur Urol 2007; 52:56549873.

499 Vloeberghs V., Verheyen G., Haentjens P., Goossens A., Polyzos N P., Tournaye H. How 500 successful is TESE-ICSI in couples with non-obstructive azoospermia? Hum Reprod 2015; 30: $501 \quad 1790-6$.

502 Wiegel M, Meston C, Rosen R. The Female Sexual Function Index (FSFI): Cross-validation and 503 development of clinical cutoff scores. J Sex Marital Ther 2005;31:1-20.

504 Wordecha Małgorzata., Wilk Mateusz., Kowalewska Ewelina., Skorko Maciej., Lapiński Adam., 505 Gola Mateusz. "Pornographic binges" as a key characteristic of males seeking treatment for 506 compulsive sexual behaviors: Qualitative and quantitative 10-week-long diary assessment. J 507 Behav Addict 2018; 7: 433-444.

508 World Association for Sexual Health (2006) Working Definitions after WHO Technical 509 Consultation on Sexual Health. Accessed July 2011.

510 World Health Organization (2002) Report of a technical consultation on sexual health. Accessed 511 August 2011.

512 World Health Organization. WHO Laboratory Manual for the Examination and Processing of 513 Human Semen, 5th edn. Geneva, Switzerland: WHO press, 2010.

514 Yuksel Bahar, Ozgor Faruk. Effect of the COVID-19 pandemic on female sexual behavior. Int J 515 Gynaecol Obstet 2020; 150: 98-102. 


\section{Figure Caption}

518 Fig 1. Association between psychological health and sexual function in couples with azoospermia 519 using the Actor-Partner Interdependence Model.

520 Observed variables are shown within rectangles. Significant values are shown in red and solid line, 521 no significant correlations in blue and dashed line. IIEF-15 represent male sexual function, FSFI 522 represent female sexual function. GAD-7 and PHQ-9 represent anxiety and depression symptoms, 523 respectively. For men, IIEF-15 negatively correlated with their own GAD-7 $(\beta=-0.22, S E=0.04$, $524 Z=-5.08, p=0.00)$ and PHQ-9 $(\beta=-0.21, S E=0.05, Z=-4.46, p=0.00)$ but not with their 525 partner's GAD-7 $(\beta=-0.00, \mathrm{SE}=0.04, \mathrm{Z}=-0.07, p=0.94)$ and PHQ-9 $(\beta=0.01, \mathrm{SE}=0.05, \mathrm{Z}$ $526=0.25, p=0.80)$. For women, FSFI negatively correlated with their own GAD-7 $(\beta=-0.38, S E=$ $5270.09, Z=-4.46, p=0.00)$ and PHQ-9 $(\beta=-0.57, \mathrm{SE}=0.12, \mathrm{Z}=-4.89, p=0.00)$ but not with 528 their partner's GAD-7 $(\beta=-0.07, \mathrm{SE}=0.09, \mathrm{Z}=-0.77, p=0.44)$ and PHQ-9 $(\beta=-0.12, \mathrm{SE}=$ 529 $0.11, \mathrm{Z}=-1.08, p=0.28)$. 


\section{Table 1 (on next page)}

Table 1. Participants' demographic characteristics 
1 Table 1. Participants' demographic characteristics.

\begin{tabular}{|c|c|c|c|c|c|c|c|c|c|c|}
\hline \multirow[b]{2}{*}{ Characteristics } & \multicolumn{2}{|c|}{$\begin{array}{c}\text { Male }(\mathrm{n}=200) \\
\text { Mean } \pm \mathrm{SD} / \mathrm{n}(\%)\end{array}$} & \multicolumn{8}{|c|}{$\begin{array}{c}\text { Female }(n=200) \\
\text { Mean } \pm \text { SD/n }(\%)\end{array}$} \\
\hline & $\begin{array}{l}\text { Azoospermia } \\
(\mathrm{n}=100)\end{array}$ & $\begin{array}{l}\text { Normozoosper } \\
\text { mia } \\
(\mathrm{n}=100)\end{array}$ & Statistics & $\begin{array}{l}\text { Effect } \\
\text { size } \\
(\mathrm{d} \text { or } \mathrm{V})\end{array}$ & $\begin{array}{l}P 1 \\
\text { value }\end{array}$ & $\begin{array}{l}\text { Azoospermia } \\
(\mathrm{n}=100)\end{array}$ & $\begin{array}{l}\text { Normozoosper } \\
\text { mia } \\
(\mathrm{n}=100)\end{array}$ & Statistics & $\begin{array}{l}\text { Effect } \\
\text { size } \\
(\mathrm{d} \text { or } \mathrm{V})\end{array}$ & $\begin{array}{l}P 2 \\
\text { value }\end{array}$ \\
\hline Age (years) & $34.52 \pm 4.71$ & $34.95 \pm 4.00$ & $\mathrm{t}=-0.70$ & $\mathrm{~d}=-0.10$ & 0.49 & $32.76 \pm 4.32$ & $33.51 \pm 4.42$ & $\mathrm{t}=-1.21$ & $\mathrm{~d}=-0.17$ & 0.23 \\
\hline BMI $\left(\mathrm{kg} / \mathrm{m}^{2}\right)$ & $25.48 \pm 3.49$ & $25.47 \pm 3.72$ & $\mathrm{t}=0.03$ & $\mathrm{~d}=0.00$ & 0.98 & $22.86 \pm 3.33$ & $23.33 \pm 3.35$ & $\mathrm{t}=-1.00$ & $\mathrm{~d}=-0.14$ & 0.32 \\
\hline Income $(\%)$ & & & $\chi^{2}=1.02$ & $\mathrm{~V}=0.13$ & 0.54 & & & $\chi^{2}=0.42$ & $\mathrm{~V}=0.05$ & 0.40 \\
\hline Low & $23(23.0)$ & $26(26.0)$ & & & & $45(45.0)$ & $43(43.0)$ & & & \\
\hline Middle & $59(59.0)$ & $61(61.0)$ & & & & $44(44.0)$ & $48(48.0)$ & & & \\
\hline High & $18(18.0)$ & $13(13.0)$ & & & & $11(11.0)$ & $9(9.0)$ & & & \\
\hline Education & & & $\chi^{2}=3.76$ & $\mathrm{~V}=0.14$ & 0.30 & & & $\chi^{2}=15.78$ & $\mathrm{~V}=0.28$ & $0.00 *$ \\
\hline $\begin{array}{l}\text { High school and } \\
\text { below }\end{array}$ & $34(34.0)$ & $23(23.0)$ & & & & $27(27.0)$ & $30(30.0)$ & & & \\
\hline $\begin{array}{l}\text { College for } \\
\text { professional } \\
\text { training }\end{array}$ & $19(19.0)$ & $22(22.0)$ & & & & $30(30.0)$ & $19(19.0)$ & & & \\
\hline Undergraduate & $37(37.0)$ & $47(47.0)$ & & & & $24(24.0)$ & $45(45.0)$ & & & \\
\hline $\begin{array}{l}\text { Postgraduate and } \\
\text { above }\end{array}$ & $10(10.0)$ & $8(8.0)$ & & & & $19(19.0)$ & $6(6.0)$ & & & \\
\hline Smoker & $41(41.0)$ & $39(39.0)$ & $\chi^{2}=0.08$ & $\mathrm{~V}=0.02$ & 0.89 & $6(6.0)$ & $4(4.0)$ & $\chi^{2}=0.42$ & $\mathrm{~V}=0.05$ & 0.75 \\
\hline Drinking alcohol & & & $\chi^{2}=3.50$ & $\mathrm{~V}=0.13$ & 0.49 & & & $\chi^{2}=8.11$ & $\mathrm{~V}=0.20$ & $0.03 *$ \\
\hline $\begin{array}{l}\text { Almost every } \\
\text { day }\end{array}$ & $2(2.0)$ & $1(1.0)$ & & & & 0 & 0 & & & \\
\hline Often & $7(7.0)$ & $4(4.0)$ & & & & $2(2.0)$ & $1(1.0)$ & & & \\
\hline Sometimes & $23(23.0)$ & $27(27.0)$ & & & & $15(15.0)$ & $4(4.0)$ & & & \\
\hline Rarely & $47(47.0)$ & $39(39.0)$ & & & & $38(38.0)$ & $38(38.0)$ & & & \\
\hline Never & $21(21.0)$ & $29(29.0)$ & & & & $45(45.0)$ & $57(57.0)$ & & & \\
\hline
\end{tabular}




\begin{tabular}{|c|c|c|c|c|c|c|c|c|c|c|}
\hline $\begin{array}{l}\text { Frequency of } \\
\text { physical } \\
\text { exercise }\end{array}$ & & & $\chi^{2}=0.55$ & $\mathrm{~V}=0.05$ & 0.76 & & & $\chi^{2}=1.92$ & $\mathrm{~V}=0.10$ & 0.17 \\
\hline None & $23(23.0)$ & $24(24.0)$ & & & & $40(40.0)$ & $31(31.0)$ & & & \\
\hline $\begin{array}{l}\leq 2 \text { times a } \\
\text { month }\end{array}$ & $29(29.0)$ & $33(33.0)$ & & & & $29(29.0)$ & $31(31.0)$ & & & \\
\hline $\begin{array}{l}\geq 3 \text { times a } \\
\text { month }\end{array}$ & $48(48.0)$ & $43(43.0)$ & & & & $31(31.0)$ & $38(38.0)$ & & & \\
\hline Stress level & & & $\chi^{2}=2.61$ & $\mathrm{~V}=0.11$ & 0.30 & & & $\chi^{2}=2.27$ & $\mathrm{~V}=0.11$ & 0.30 \\
\hline High & $43(43.0)$ & $32(32.0)$ & & & & $30(30.0)$ & $27(27.0)$ & & & \\
\hline General & $48(48.0)$ & $58(58.0)$ & & & & $44(44.0)$ & $54(54.0)$ & & & \\
\hline Low & $9(9.0)$ & $10(10.0)$ & & & & $26(26.0)$ & $19(19.0)$ & & & \\
\hline
\end{tabular}

2 BMI: body mass index

$* p<0.05$

4

5

6 


\section{Table 2 (on next page)}

Table 2. Comparison of sexual health between men with azoospermia and normozoospermia 
1 Table 2. Comparison of sexual health between men with azoospermia and normozoospermia

\begin{tabular}{|c|c|c|c|c|c|}
\hline Items & $\begin{array}{c}\text { Azoospermic men } \\
\qquad(\mathrm{n}=100) \\
\mathrm{n}(\%) / \text { Mean } \pm \mathrm{SD}\end{array}$ & $\begin{array}{c}\text { Normozoospermic men } \\
(\mathrm{n}=100) \\
\mathrm{n}(\%) / \text { Mean } \pm \mathrm{SD}\end{array}$ & Statistics & $\begin{array}{l}\text { Effect size } \\
(d \text { or } V)\end{array}$ & $P$ value \\
\hline Sexual satisfaction & & & $\chi^{2}=7.32$ & $\mathrm{~V}=0.19$ & $0.02 *$ \\
\hline Satisfied & $56(56.0)$ & $70(70.0)$ & & & \\
\hline Neutral & $20(20.0)$ & $20(20.0)$ & & & \\
\hline Dissatisfied & $24(24.0)$ & $10(10.0)$ & & & \\
\hline $\begin{array}{l}\text { Sexual life frequency (per } \\
\text { month) }\end{array}$ & $4.14 \pm 2.72$ & $5.04 \pm 2.25$ & $\mathrm{t}=-2.55$ & $d=-0.36$ & $0.01 *$ \\
\hline IIEF-15 score & $53.07 \pm 11.11$ & $57.52 \pm 8.57$ & $\mathrm{t}=-3.17$ & $d=-0.45$ & $0.00 * *$ \\
\hline Erectile function score & $23.25 \pm 5.13$ & $24.82 \pm 4.18$ & $\mathrm{t}=-2.37$ & $\mathrm{~d}=-0.34$ & $0.02 *$ \\
\hline Orgasmic function score & $7.34 \pm 1.82$ & $8.04 \pm 1.48$ & $\mathrm{t}=-2.98$ & $d=-0.42$ & $0.00 * *$ \\
\hline Sexual desire score & $6.07 \pm 1.37$ & $6.24 \pm 1.29$ & $\mathrm{t}=-0.90$ & $d=-0.13$ & 0.37 \\
\hline Intercourse satisfaction score & $9.45 \pm 2.71$ & $10.55 \pm 2.18$ & $\mathrm{t}=-3.16$ & $d=-0.45$ & $0.00 * *$ \\
\hline Overall satisfaction score & $6.96 \pm 2.24$ & $7.67 \pm 1.86$ & $\mathrm{t}=-2.44$ & $\mathrm{~d}=-0.34$ & $0.02 *$ \\
\hline Incidence of ED & & & $\chi^{2}=6.40$ & $\mathrm{~V}=0.08$ & 0.09 \\
\hline No ED (26-30) & $44(44.0)$ & $54(54.0)$ & & & \\
\hline Mild ED (22-25) & $22(22.0)$ & $25(25.0)$ & & & \\
\hline Mild to moderate ED (17-21) & $21(21.0)$ & $17(17.0)$ & & & \\
\hline Moderate ED (11-16) & $13(13.0)$ & $4(4.0)$ & & & \\
\hline Severe ED $(<11)$ & 0 & 0 & & & \\
\hline PEDT score & $6.58 \pm 3.13$ & $5.17 \pm 2.22$ & $\mathrm{t}=3.67$ & $\mathrm{~d}=0.52$ & $0.00 * *$ \\
\hline Incidence of PE & & & $\chi^{2}=14.73$ & $\mathrm{~V}=0.27$ & $0.00 * *$ \\
\hline No PE $(\leq 8)$ & $65(65.0)$ & $85(85.0)$ & & & \\
\hline Probable PE (9-10) & $22(22.0)$ & $14(14.0)$ & & & \\
\hline $\mathrm{PE}(\geq 11)$ & $13(13.0)$ & $1(1.0)$ & & & \\
\hline
\end{tabular}

2 IIEF-15: International Index of Erectile Dysfunction; ED: Erectile dysfunction; PEDT:

3 Premature Ejaculation Diagnostic Tool; PE: Premature ejaculation

$4 * p<0.05 * * p<0.01$ 


\section{Table 3 (on next page)}

Table 3. Comparison of sexual health between wives of men with azoospermia and normozoospermia. 
1 Table 3. Comparison of sexual health between wives of men with azoospermia and 2 normozoospermia.

3

\begin{tabular}{|c|c|c|c|c|c|}
\hline Items & $\begin{array}{c}\text { Azoospermia } \\
(\mathrm{n}=100) \\
\mathrm{n}(\%) / \text { Mean } \pm \mathrm{SD}\end{array}$ & $\begin{array}{c}\text { Normozoospermia } \\
(\mathrm{n}=100) \\
\mathrm{n}(\%) / \text { Mean } \pm \mathrm{SD}\end{array}$ & Statistics & $\begin{array}{l}\text { Effect size } \\
(\mathrm{d} \text { or } \mathrm{V})\end{array}$ & $P$ value \\
\hline Sexual satisfaction & & & $\chi^{2}=14.18$ & $\mathrm{~V}=0.27$ & $0.00 * *$ \\
\hline Satisfied & $57(57.0)$ & $72(72.0)$ & & & \\
\hline Neutral & $13(13.0)$ & $19(19.0)$ & & & \\
\hline Dissatisfied & $30(30.0)$ & $9(9.0)$ & & & \\
\hline $\begin{array}{l}\text { Sexual life frequency (per } \\
\text { month) }\end{array}$ & $3.32 \pm 2.08$ & $4.41 \pm 2.91$ & $t=-3.03$ & $d=-0.43$ & $0.00 *$ \\
\hline FSFI score & $25.12 \pm 5.56$ & $26.75 \pm 4.82$ & $\mathrm{t}=-2.22$ & $\mathrm{~d}=-0.31$ & $0.03 *$ \\
\hline Sexual desire score & $3.39 \pm 0.85$ & $3.31 \pm 0.86$ & $t=0.66$ & $\mathrm{~d}=0.09$ & 0.49 \\
\hline $\begin{array}{l}\text { Sexual arousal ability } \\
\text { score }\end{array}$ & $3.84 \pm 1.15$ & $3.96 \pm 1.13$ & $\mathrm{t}=-0.74$ & $d=-0.11$ & 0.46 \\
\hline Vaginal lubricity score & $4.85 \pm 1.02$ & $5.12 \pm 0.93$ & $t=-1.96$ & $\mathrm{~d}=-0.28$ & 0.05 \\
\hline Orgasm score & $4.22 \pm 1.26$ & $4.60 \pm 1.03$ & $\mathrm{t}=-2.33$ & $\mathrm{~d}=-0.33$ & $0.02 *$ \\
\hline Sexual satisfaction score & $4.10 \pm 1.39$ & $4.72 \pm 1.09$ & $\mathrm{t}=-3.51$ & $d=-0.50$ & $0.00 * *$ \\
\hline Coital pain score & $4.72 \pm 1.06$ & $6.04 \pm 0.92$ & $\mathrm{t}=-9.40$ & $\mathrm{~d}=-1.33$ & $0.02 *$ \\
\hline $\begin{array}{l}\text { Incidence of sexual } \\
\text { dysfunction }\end{array}$ & $33(33.0)$ & $21(21.0)$ & $\chi^{2}=3.03$ & $\mathrm{~V}=0.12$ & 0.05 \\
\hline
\end{tabular}

4 FSFI: Female Sexual Function Index

$5 * p<0.05 * * p<0.01$

6 


\section{Table 4(on next page)}

Table 4. Changes in sexual behaviours of couples with azoospermia and normozoospermia during the lockdown. 


\begin{tabular}{|c|c|c|c|c|c|c|c|c|c|c|}
\hline \multirow[t]{2}{*}{ Items } & \multicolumn{2}{|c|}{ Men } & \multicolumn{8}{|c|}{ Women } \\
\hline & $\begin{array}{l}\text { Azoospermia } \\
(\mathrm{n}=100) \\
\mathrm{n}(\%) / \text { Mean } \pm \mathrm{SD}\end{array}$ & $\begin{array}{c}\text { Normozoospermia } \\
(\mathrm{n}=100) \\
\mathrm{n}(\%) / \text { Mean } \pm \mathrm{SD}\end{array}$ & Statistics & $\begin{array}{l}\text { Effect } \\
\text { size } \\
(V)\end{array}$ & $\begin{array}{c}P \\
\text { value }\end{array}$ & $\begin{array}{c}\text { Azoospermia } \\
(\mathrm{n}=100) \\
\mathrm{n}(\%) / \text { Mean } \\
\pm \mathrm{SD}\end{array}$ & $\begin{array}{l}\text { Normozoospermia } \\
\quad(\mathrm{n}=100) \\
\mathrm{n}(\%) / \text { Mean } \pm \mathrm{SD}\end{array}$ & Statistics & $\begin{array}{l}\text { Effect } \\
\text { size } \\
\text { (V) }\end{array}$ & $\begin{array}{l}P \\
\text { value }\end{array}$ \\
\hline $\begin{array}{l}\text { Sexual } \\
\text { satisfaction }\end{array}$ & & & $\chi^{2}=0.71$ & $\begin{array}{l}\mathrm{V}= \\
0.06\end{array}$ & 0.70 & & & $\chi^{2}=7.22$ & $\begin{array}{l}\mathrm{V}= \\
0.19\end{array}$ & $0.03 *$ \\
\hline Increased & $2(2.0)$ & $2(2.0)$ & & & & $5(5.0)$ & $3(3.0)$ & & & \\
\hline Unchanged & $83(83.0)$ & $87(87.0)$ & & & & $76(76.0)$ & $90(90.0)$ & & & \\
\hline Decreased & $15(15.0)$ & $11(11.0)$ & & & & $19(19.0)$ & $7(7.0)$ & & & \\
\hline Sexual desire & & & $\chi^{2}=0.00$ & $\begin{array}{l}\mathrm{V}= \\
0.00\end{array}$ & 1.00 & & & $\chi^{2}=2.79$ & $\begin{array}{l}\mathrm{V}= \\
0.12\end{array}$ & 0.25 \\
\hline Increased & $4(4.0)$ & $4(4.0)$ & & & & $7(7.0)$ & $5(4.0)$ & & & \\
\hline Unchanged & $83(83.0)$ & $83(83.0)$ & & & & $77(77.0)$ & $86(87.0)$ & & & \\
\hline Decreased & $13(13.0)$ & $13(13.0)$ & & & & $16(16.0)$ & $9(9.0)$ & & & \\
\hline $\begin{array}{l}\text { Sexual } \\
\text { frequency }\end{array}$ & & & $\chi^{2}=0.23$ & $\begin{array}{l}\mathrm{V}= \\
0.03\end{array}$ & 0.89 & & & $\chi^{2}=1.73$ & $\begin{array}{l}V= \\
0.09\end{array}$ & 0.42 \\
\hline Increased & $4(4.0)$ & $5(5.0)$ & & & & $7(7.0)$ & $4(4.0)$ & & & \\
\hline Unchanged & $77(77.0)$ & $78(78.0)$ & & & & $78(78.0)$ & $85(85.0)$ & & & \\
\hline Decreased & $19(19.0)$ & $17(17.0)$ & & & & $15(15.0)$ & $11(11.0)$ & & & \\
\hline $\begin{array}{l}\text { Frequency of } \\
\text { masturbation }\end{array}$ & & & $\chi^{2}=4.62$ & $\begin{array}{l}\mathrm{V}= \\
0.15\end{array}$ & 0.20 & & & $\begin{array}{l}\chi^{2}= \\
21.96\end{array}$ & $\begin{array}{l}\mathrm{V}= \\
0.33\end{array}$ & $\begin{array}{l}0.00 * \\
*\end{array}$ \\
\hline Increased & $12(12.0)$ & $6(6.0)$ & & & & $24(24.0)$ & $2(2.0)$ & & & \\
\hline Unchanged & $45(45.0)$ & $46(46.0)$ & & & & $32(32.0)$ & $41(41.0)$ & & & \\
\hline Decreased & $23(23.0)$ & $18(18.0)$ & & & & $6(6.0)$ & $11(11.0)$ & & & \\
\hline None & $20(20.0)$ & $30(30.0)$ & & & & $38(38.0)$ & $46(46.0)$ & & & \\
\hline
\end{tabular}


Frequency of pornography use

Unchanged

Decreased

None

$$
\begin{array}{lll}
\chi^{2}=2.71 & \mathrm{~V}= & 0.44 \\
& 0.12 &
\end{array}
$$

$$
\chi^{2}=
$$$$
\mathrm{V}=
$$$$
0.01 *
$$

10.90

0.23

$17(17.0) \quad 3(3.0)$

$23(23.0) \quad 27(27.0)$

$4(4.0) \quad 5(5.0)$

$56(56.0) \quad 65(65.0)$

$3 \quad * \mathrm{P}<0.05, * * \mathrm{P}<0.01$ 


\section{Table 5 (on next page)}

Table 5. Psychological health of couples with azoospermia and normozoospermia in the context of the COVID-19 pandemic 


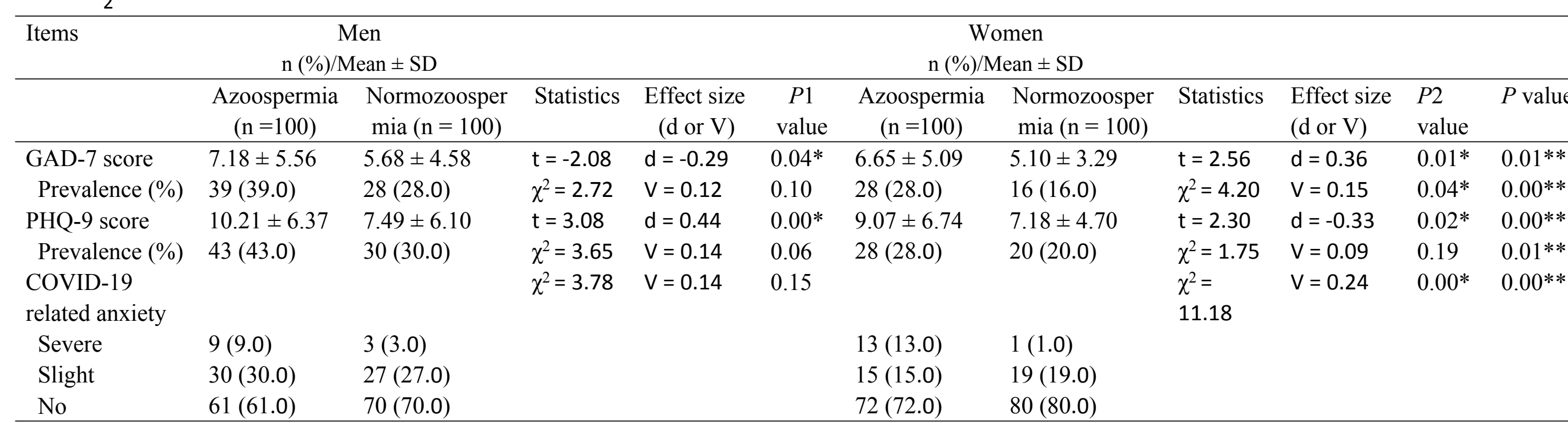

$3 \quad P 1$ : men with azoospermia compared with normozoospermia

$4 \quad P 2$ : the wives of men with azoospermia compared with normozoospermia

$5 \quad P$ : couples with azoospermia compared with normozoospermia

6 GAD-7: Generalized Anxiety Disorder-7; PHQ-9: Patient Health Questionnaire-9

$7 * \mathrm{P}<0.05, * * \mathrm{P}<0.01$ 


\section{Figure 1}

Association between psychological health and sexual function in couples with azoospermia using the Actor-Partner Interdependence Model

Observed variables are shown within rectangles. Significant values are shown in red and solid line, no significant correlations in blue and dashed line. IIEF-15 represent male sexual function, FSFI represent female sexual function. GAD-7 and PHQ-9 represent anxiety and depression symptoms, respectively. For men, IIEF-15 negatively correlated with their own GAD-7 $(\beta=-0.22, S E=0.04, Z=-5.08, p=0.00)$ and PHQ-9 $(\beta=-0.21, S E=0.05, Z=$ $-4.46, p=0.00)$ but not with their partner's GAD-7 ( $\beta=-0.00, \mathrm{SE}=0.04, \mathrm{Z}=-0.07, p=$ 0.94) and PHQ-9 $(\beta=0.01, \mathrm{SE}=0.05, \mathrm{Z}=0.25, p=0.80)$. For women, FSFI negatively correlated with their own GAD-7 $(\beta=-0.38, S E=0.09, Z=-4.46, p=0.00)$ and PHQ-9 $(\beta=$ $-0.57, \mathrm{SE}=0.12, \mathrm{Z}=-4.89, p=0.00)$ but not with their partner's GAD-7 $(\beta=-0.07, \mathrm{SE}=$ $0.09, Z=-0.77, p=0.44)$ and PHQ-9 $(\beta=-0.12, \mathrm{SE}=0.11, \mathrm{Z}=-1.08, p=0.28)$. 


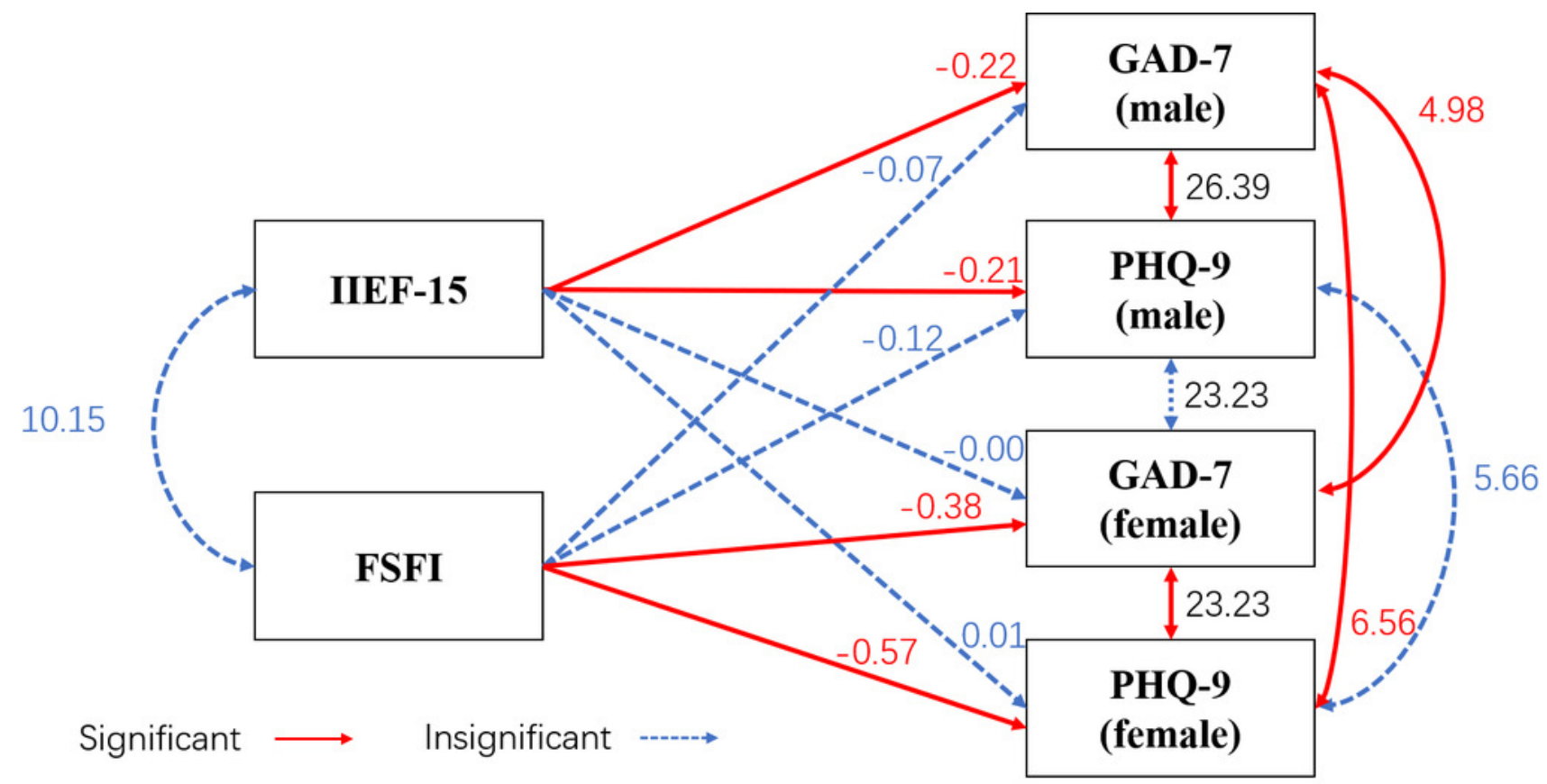

